\title{
Derivation of Life Cycle Cost Model for Selecting Optimum Decisions in Engineering Asset Management
}

\author{
W.N. Cahyo \\ Department of Industrial Engineering, Faculty of Industrial Technology, Islamic University of Indonesia, Jl. Kaliurang Km. 14.4, Sleman \\ Yogyakarta, Indonesia
}

\begin{abstract}
It is common that interdepartmental conflict may arise in an organisation to select which decision to be taken, especially in the area of engineering asset management. In this paper, an engineering asset management related case study is discussed and a derivation of a life cycle cost model is proposed to assist finding the optimum decision. Another challenge in this study is a situation that the data and information required to calculate the total cost is unavailable. To deal with this situation, a cost comparison approach is proposed as well as a sensitivity analysis in order to select the optimum decision if the uncontrolled variable in the system nature changes. The result shows that the total cost model derived from the life cycle cost model is capable to assist selecting the optimum decision. A simple spreadsheet based Monte Carlo model is also developed to represent the randomness of the time to failure during the five years of time horizon of the analysis.
\end{abstract}

\section{Introduction}

The main purpose of asset management is to balance between cost, performance and risk involved in the asset [1]. It leads to essential functions of asset management in making asset-related important decisions in a corporate level. However, it also may generate disputes between different departments related to asset, such as in making decision to keep or dispose the asset, or decision to keep the scheduled maintenance interval suggested by the manufacturer or change the interval. In making decision related to asset, conflict of interest between departments might happen. In General, the departments involved in this dispute are production (operation), maintenance, purchasing, and finance. It is understandable that the main reason of the conflict is they have their own KPIs to achieve.

To deal with this issue, it is suggested that the related departments should seek a solution that provide global optimum in the corporate level instead of local optimum in the departmental level. Referring to the purpose of asset management, the optimised decision must involve cost, performance, and risk as the main constraint in the decision. To help the decision maker to select what decision to make correct decision, a mathematical model can be suggested. In this paper, a mathematical model is developed to support the process of solving the asset management disputing case. The mathematical model is derived from a pre-developed in Life Cycle Cost model in [2]. The main reason of using the life cycle cost model is based on a consideration that the dispute happens during the life cycle delivery of the asset, so that the life cycle cost can assist to determine which policy may generate lower cost. After the desired mathematical cost model is attained, then the model is verified in the discussed case study to verify whether the model is capable to assist in the process of making a better asset related decision.

\section{Life Cycle Cost Model for Asset- Related Decision Making}

Life cycle cost model can be implemented in various fields, such as manufacturing [3, 4]; public infrastructure [5] to power plant $[6,7]$. In the area of asset management, life cycle cost can be used as a dominant criterion in making decision related to asset [8]. The main concern of asset management is managing the engineering asset through their life cycle to achieve the purpose of the organisation $[8,9]$. According to the Institute of Asset Management, there are 6 subject groups in the Conceptual Model of Asset Management. One of the subject groups is the life cycle delivery which includes activities for asset acquisition, asset operation, asset maintenance, and asset disposal. According to [10], all technical system is a physical asset and it goes through different stages during its useful life. Those stages are the stages in the asset life cycle. The activities in the asset life cycle delivery are complex and may consume considerably large amount of financial resource $[11,12]$. In this respect, it is important to optimise the cost generated from the asset life cycle delivery as well as maintaining the performance of the asset. The process of optimising the asset performance throughout its life cycles requires the use of life cycle cost analysis and models for such performance optimisation [11, 13-16]. It means that life cycle cost model is very useful to 
assist management to make any decision related to their asset in the asset management framework [16].

The use of life cycle cost in supporting the management to make decision in the area of engineering asset management has been observed in [16]. In that article, the authors have observed the different use of life cycle cost model in the asset management decision. Briefly, there are five different categories of the use of life cycle cost model is proposed by the authors. One application of the life cycle cost model is to develop a value oriented decision support system in the area of maintenance and replacement or restoration. The example of a complete life cycle cost model that covers all stages in the asset life cycle is presented in [2] and [17]. As thoroughly discussed in [2] that the life cycle cost model has been verified and tailored to different asset management case study case studies and it is capable to serve its purpose. It is also indicated that in [11] the mathematical model of the total cost to select the maintenance policy is derived from a life cycle cost model presented in [2]. Based on this similarities, the life cycle cost model can be employed as a basis model to serve the purpose of this study.

\section{Case Study and Analysis}

The case study presented in this paper is a case from a government-owned manufacture industry and it is related to a decision for buying a machine spare-part, which is bearing, with a particular specification but different price and quality. There are some argues from different departments in regard to which bearing that should be bought; cheaper one with less reliability or one with more reliability but more expensive. The purchasing department and the finance department suggest buying the lower price bearing to save the expenses but the maintenance department and production department recommend buying the more expensive one because of the reliability reason. Resolving this conflict is the main purpose of this study. This type of asset-related conflict of interest may happen in many different ways in different organisations. It is common that when every department tends to achieve or maintain their Key Performance Indicator (KPI). One of the KPIs of the maintenance department is asset reliability. Asset reliability leads to the reliability of the production system however it may require more cost. Conversely, the finance department is responsible to maintain and push the cost down as one of their KPIs. In this case study, reliability and cost are the conflicting KPI of these departments.

Referring to ISO 55000 that the implementation of asset management should involve balancing cost, risk, and performance. It should be noted that these aspects should be balanced in all asset related process and decision making and mainly to ensure that the asset is capable to meet its function in the process of achieving organisation's competitive strategy [9]. Based on this logic, it can be highlighted that instead of achieving local optimum at the departmental level (either in maintenance, production, purchasing, or finance), it is proposed to achieve global optimum at the corporate level by optimising the combination of cost, risk, and performance. In order to be able to represent this process of analysis, a Life Cycle Cost model can be employed. In developing the life cycle cost model, the risk and performance is also important to be considered. In other words, the life cycle cost model should associate the risk and performance as the cost components.

\section{Model Development and Discussion}

It is proposed in this paper that to resolve the interdepartmental conflict discussed in the case study, life cycle cost model is used. However, the model is modified and tailored as necessary. It is also to verify that a complete life cycle cost model (e.g. as presented in [2]) can be modified and tailored to provide decision makers with a guidance to attain an optimum asset related decision considering the balance of cost, risk, and performance of the asset. The develop the cost model for the case study in this paper, life cycle cost in [2] is used as the basis model as shown in Equation (1) and (2).

$$
\begin{aligned}
& \mathrm{LCC}=\quad \sum_{\mathrm{t}=1}^{\mathrm{td}}\left[\mathrm{C}_{\mathrm{u}, \mathrm{t}}(\mathrm{MTBF}, \mathrm{MTTR})(\mathrm{m}, \mathrm{t}+\mathrm{s}, \mathrm{t})+\right. \\
& \mathrm{F}_{\mathrm{o}, \mathrm{t}}+\mathrm{A}_{\mathrm{sys}} \mathrm{C}_{\mathrm{o}, \mathrm{t}} \mathrm{m}+\sum_{\mathrm{r}=1}^{\mathrm{n}_{\mathrm{t}, \mathrm{t}}}\left(\mathrm{F}_{\mathrm{SM}, \mathrm{r}, \mathrm{t}}+\mathrm{C}_{\mathrm{SM}, \mathrm{r}, \mathrm{t}}\right)+ \\
& \sum_{\mathrm{s}=1}^{\mathrm{n}_{\mathrm{U}, \mathrm{t}}}\left(\mathrm{F}_{\mathrm{UM}, \mathrm{s}, \mathrm{t}}+\mathrm{C}_{\mathrm{UM}, \mathrm{s}, \mathrm{t}}\right)+\mathrm{n}_{\mathrm{d}, \mathrm{t}} \cdot \mathrm{F}_{\mathrm{SL}, \mathrm{t}}+\mathrm{T}_{\mathrm{d}, \mathrm{t}} \cdot \mathrm{C}_{\mathrm{S}, \mathrm{t}}+ \\
& \left(\mathrm{n}_{\mathrm{HR}, \mathrm{t}} \cdot \mathrm{L}_{\mathrm{t}}\right)+\sum_{\mathrm{l}=1}^{\mathrm{n}_{\mathrm{p}, \mathrm{t}}}\left(\frac{\mathrm{t}_{\mathrm{p}, \mathrm{t}, \mathrm{t}}}{365} \cdot \mathrm{L}_{\mathrm{t}}\right)+\left[\left(\mathrm{n}_{\mathrm{R}, \mathrm{t}} \cdot \mathrm{F}_{\mathrm{R}, \mathrm{t}}\right)+\right. \\
& \left.\sum_{\mathrm{p}=1}^{\mathrm{n}_{\mathrm{R}, \mathrm{t}}}\left(\mathrm{n}_{\mathrm{NHR}, \mathrm{p}, \mathrm{t}} \cdot \frac{\mathrm{t}_{\mathrm{NHR}, \mathrm{p}, \mathrm{t}}}{365} \cdot \mathrm{L}_{\mathrm{t}}\right)\right]+\left[\left(\mathrm{n}_{\mathrm{RO}, \mathrm{t}} \cdot \mathrm{F}_{\mathrm{RO}, \mathrm{t}}\right)+\right. \\
& \left.\sum_{\mathrm{q}=1}^{\mathrm{n}_{\mathrm{R}, \mathrm{t}}}\left(\mathrm{n}_{\mathrm{o}, \mathrm{q}, \mathrm{t}} \cdot \mathrm{C}_{\mathrm{o}, \mathrm{q}, \mathrm{t}}\right)\right]+\mathrm{F}_{\mathrm{i}, \mathrm{t}}+\left(\mathrm{n}_{\mathrm{p}, \mathrm{t}} \cdot \mathrm{C}_{\mathrm{p}, \mathrm{t}}\right)+ \\
& \left(\mathrm{n}_{\mathrm{c}, \mathrm{t}} \cdot \mathrm{C}_{\mathrm{i}, \mathrm{t}}\right)+\left(\frac{\left(\mathrm{n}_{i, t}+\mathrm{n}_{\mathrm{c}, \mathrm{t}}\right.}{365} \cdot \mathrm{C}_{\mathrm{inv}, \mathrm{t}}\right)-\mathrm{S}_{\mathrm{a}, \mathrm{t}}(\mathrm{m}, \mathrm{t}+ \\
& \mathrm{s}, \mathrm{t})](1+\pi)^{\mathrm{t}-1}(1+\mathrm{r})^{-\mathrm{t}}
\end{aligned}
$$

$\mathrm{LCC}_{\mathrm{t}}=\mathrm{C}_{\mathrm{A}, \mathrm{t}}+\mathrm{F}_{\mathrm{o}, \mathrm{t}}+\mathrm{C}_{\mathrm{o}, \mathrm{t}}+\mathrm{C}_{\mathrm{M}, \mathrm{t}}+\mathrm{C}_{\mathrm{SL}, \mathrm{t}}+\mathrm{C}_{\mathrm{HR}, \mathrm{t}}+\mathrm{C}_{\mathrm{PI}, \mathrm{t}}+\mathrm{C}_{\mathrm{S}, \mathrm{t}}(2)$

where

$\mathrm{LCC}_{\mathrm{t}} \quad$ : Total Life Cycle Cost at time $\mathrm{t}$

$\mathrm{C}_{\mathrm{A}, \mathrm{t}} \quad$ : acquisition cost at time $\mathrm{t}$

$\mathrm{F}_{\mathrm{o}, \mathrm{t}} \quad$ : fixed cost of operating at time $\mathrm{t}$

$\mathrm{C}_{\mathrm{o}, \mathrm{t}} \quad$ : annual operating cost at time $\mathrm{t}$

$\mathrm{C}_{\mathrm{M}, \mathrm{t}} \quad$ : maintenance cost at time $\mathrm{t}$

$\mathrm{C}_{\mathrm{SL}, \mathrm{t}} \quad$ : stoppage loss at time $\mathrm{t}$

$\mathrm{C}_{\mathrm{HR}, \mathrm{t}}$ : human resource provisioning cost at time $\mathrm{t}$

$\mathrm{C}_{\mathrm{PI}, \mathrm{t}} \quad$ : purchasing and inventory cost at time $\mathrm{t}$

$\mathrm{C}_{\mathrm{S}, \mathrm{t}} \quad$ : salvage value at time $\mathrm{t}$

The life cycle cost in equation consists of eight cost component as shown in equation 2. An investigation has been done to identify what cost components used related to the case study. From the investigation, it is determined that the cost components retained in the model are maintenance cost, stoppage loss, and purchasing and inventory cost as shown in Table 1. 
Table 1. The cost component for the new model

\begin{tabular}{|c|c|c|}
\hline No & Cost components & Equation \\
\hline 1 & Maintenance cost & $\begin{array}{l}\sum_{\mathrm{r}=1}^{\mathrm{n}_{\mathrm{SM}}}\left(\mathrm{F}_{\mathrm{SM}, \mathrm{r}}+\mathrm{C}_{\mathrm{SM}, \mathrm{r}}\right)+ \\
\sum_{\mathrm{S}=1}^{\mathrm{n}_{\mathrm{UM}}}\left(\mathrm{F}_{\mathrm{UM}, \mathrm{S}}+\mathrm{C}_{\mathrm{UM}, \mathrm{S}}\right)\end{array}$ \\
\hline 2 & Stoppage loss & $\mathrm{n}_{\mathrm{d}} \cdot \mathrm{F}_{\mathrm{SL}}+\mathrm{T}_{\mathrm{d}} \cdot \mathrm{C}_{\mathrm{S}}$ \\
\hline 3 & $\begin{array}{l}\text { Purchasing and } \\
\text { inventory cost }\end{array}$ & $\begin{array}{l}\mathrm{F}_{\mathrm{i}}+\left(\mathrm{n}_{\mathrm{p}} \cdot \mathrm{C}_{\mathrm{p}}\right)+\left(\mathrm{n}_{\mathrm{c}} \cdot \mathrm{C}_{\mathrm{i}}\right)+ \\
\left(\frac{\mathrm{n}_{i}+\mathrm{n}_{\mathrm{c}}}{365} \cdot \mathrm{C}_{\mathrm{inv}}\right)\end{array}$ \\
\hline
\end{tabular}

Where :

$\mathrm{F}_{\mathrm{SM}} \quad$ : fixed cost of scheduled maintenance

$\mathrm{C}_{\mathrm{SM}} \quad$ : total variable cost for every scheduled maintenance performed

$\mathrm{F}_{\mathrm{UM}} \quad$ : fixed cost of unscheduled maintenance

$\mathrm{C}_{\mathrm{UM}} \quad$ : total variable cost for every unscheduled maintenance performed

$\mathrm{n}_{\mathrm{d}} \quad$ : number of stoppage occurrences

$\mathrm{F}_{\mathrm{SL}} \quad$ : Fixed cost of a unit's stoppage

$\mathrm{T}_{\mathrm{d}} \quad$ : amount of time the units fail

$\mathrm{C}_{\mathrm{S}} \quad$ : opportunity loss per measured time

$\mathrm{F}_{\mathrm{i}} \quad$ : Fixed purchasing and inventory cost

$\mathrm{n}_{\mathrm{p}} \quad$ : number of purchases

$\mathrm{C}_{\mathrm{p}} \quad$ : purchasing cost

$\mathrm{n}_{\mathrm{i}} \quad$ : number of initial inventories

$\mathrm{n}_{\mathrm{c}} \quad:$ number of components purchased

$\mathrm{C}_{\mathrm{i}} \quad$ : cost of a component

$\mathrm{C}_{\text {inv }} \quad$ : inventory cost

The main reason of retaining the three cost component is because those components present the process of balancing risk, performance, and cost at a particular time frame as mentioned in [1]. Although it is possible to retain other cost components such as annual operating cost, and human resources provisioning cost, it is assumed that other cost components will not significantly affect the decision since those cost component has similar amount regardless what decision alternatives proposed. To fit with the case, the cost component in the Table 1 still needs to be tailored. The complete model suggested to assist making decision for this case study is shown at equation 3 .

$$
\begin{aligned}
T C= & \sum_{\mathrm{r}=1}^{\mathrm{n}_{\mathrm{SM}}}\left(\mathrm{F}_{\mathrm{SM}, \mathrm{r}}+\mathrm{C}_{\mathrm{SM}, \mathrm{r}}\right)+\sum_{\mathrm{S}=1}^{\mathrm{n}_{\mathrm{UM}}}\left(\mathrm{F}_{\mathrm{UM}, \mathrm{s}}+\right. \\
& \left.\mathrm{C}_{\mathrm{UM}, \mathrm{s}}\right)+\mathrm{n}_{\mathrm{d}} \cdot \mathrm{F}_{\mathrm{SL}}+\mathrm{T}_{\mathrm{d}} \cdot \mathrm{C}_{\mathrm{S}}+\mathrm{F}_{\mathrm{i}}+\left(\mathrm{n}_{\mathrm{p}} \cdot \mathrm{C}_{\mathrm{p}}\right)+ \\
& \left(\mathrm{n}_{\mathrm{c}} \cdot \mathrm{C}_{\mathrm{i}}\right)+\left(\frac{\mathrm{n}_{i}+\mathrm{n}_{\mathrm{c}}}{365} \cdot \mathrm{C}_{\mathrm{inv}}\right)
\end{aligned}
$$

Since the company implements breakdown maintenance strategy, the notation for preventive maintenance cost could be eliminated. Also, it is assumed that the required time to replace the any failed bearing is similar regardless its brand. It leads to a circumstance that the breakdown maintenance cost and the stoppage loss can be combined into total cost for replacement $\left(C_{R}\right)$. The information from the company indicates that the fixed cost of purchasing and the inventory cost is relatively small and insignificantly contribute to the total cost, so that for this cost component the significant cost is from the price of the bearing. Unfortunately, the data and information required to complete the total cost equation is unavailable. To deal with this situation, a ratio cost model and a sensitivity analysis as in [18] is proposed. The cost promoted as the basis cost for the cost comparison is the cost of the normal bearing (more expensive bearing and noted as p). A spreadsheet Monte Carlo model is developed to represent the randomness of the time to failure and to analyse the sensitivity of the result. The replacement cost is assumed vary from $1 \mathrm{p}$ (replacement cost is the same amount as the component price) to $5 \mathrm{p}$ (replacement cost is five times higher than the price of the component) and the lower component price is also various from $0.3 p$ to $0.6 p$. The time to failure is assumed as Weibull distributed and random. The total cost for each combination is shown in Table 2 .

Table 2. The total cost for each combination

\begin{tabular}{|c|c|c|c|r|r|}
\hline $\mathrm{C}_{\mathrm{i}, 2} / \mathrm{C}_{\mathrm{i} .1}$ & $\mathrm{p}$ & $0.3 \mathrm{p}$ & $0.4 \mathrm{p}$ & \multicolumn{1}{c|}{$0.5 \mathrm{p}$} & \multicolumn{1}{c|}{$0.6 \mathrm{p}$} \\
\hline $1 \mathrm{p}$ & $\mathbf{1 2}$ & 9.1 & 9.8 & 10.5 & 11.2 \\
\hline $2 \mathrm{p}$ & $\mathbf{1 8}$ & 16.1 & 16.8 & 17.5 & 18.2 \\
\hline $3 \mathrm{p}$ & $\mathbf{2 4}$ & 23.1 & 23.8 & 24.5 & 25.2 \\
\hline $4 \mathrm{p}$ & $\mathbf{3 0}$ & 30.1 & 30.8 & 31.5 & 32.2 \\
\hline $5 \mathrm{p}$ & $\mathbf{3 6}$ & 37.1 & 37.8 & 38.5 & 39.2 \\
\hline
\end{tabular}

As aforementioned that the purpose for this study is to select the optimum asset related decision based on the minimum system cost. In this case study, the significant variables affect the total cost is replacement cost and the price of the component. From the Table 2, it can be concluded that if the replacement cost is as much as the cost of the normal component (1p), as long as the price of the replacement component is less or equal to $0.6 \mathrm{p}$, the cheaper component is selected. If the replacement cost increases to $2 \mathrm{p}$, the price of the cheaper component should decrease to $0.5 p$ to be feasible. In a situation when the replacement cost increases to $3 p$, the cheaper component cost more than $0.4 \mathrm{p}$ is not feasible. If the replacement cost reaches $4 \mathrm{p}$, the policy to select normal component is selected because it generates lower system cost.

\section{Conclusion}

A derivation of a life cycle cost model is developed and proposed in this model to resolve an interdepartmental case related conflict. The result shows that the model is capable to support the process of finding the optimum decision for the case presented in the case study. It is also support a hypothesis that the LCC model used as the basis of the 
derived model is sufficient to support asset-related decision making and a further study in different area and case to strengthen this statement is recommended. To deal with the situation when is incomplete data and information to complete the total cost equation, a cost ratio and sensitivity analysis is proposed. However, it is suggested that the organisation needs to review the process of purchasing to prevent this conflict as well as considering to implement asset management system in their organisation. A challenge that may arise for the future study is to develop a more robust model that is able to take into account uncertainty in the whole life cycle.

\section{References}

[1] ISO, "ISO 55000 : 2014," in Asset management Overview, principles and terminology, ed. Switzerland, 2014.

[2] W. N. Cahyo, "A modelling approach for maintenance resource-provisioning policies," Doctor of Philosophy, School of Mechanicall, Material, and Mechatronics, University of Wollongong, Wollongong - Australia, 2015.

[3] M. Gram and W. E. Schroeder, "Evaluating The Life Cycle Cost of Plant Assets - A Multidimentional View-," Serbian Journal of Management, vol. 7, p. 12, 2012.

[4] M. Sheikhalishahi and S. A. Torabi, "Maintenance supplier selection considering life cycle costs and risks: a fuzzy goal programming approach," International Journal of Production Research, vol. 52, p. 16, 2014.

[5] J. O. Almeida, P. F. Teixeira, and R. M. Delgado, "Life cycle cost optimisation in highway concrete bridges management," Structure and Infrastructure Engineering, vol. 11, p. 15, 2015.

[6] N. I. Sinisuka and H. Nugraha, "Life cycle cost analysis on the operation of power generation," Journal of Quality in Maintenance Engineering, vol. 19 , p. 20, 2013.

[7] A. Lesmerises and D. Crowley, "Effect of Different Workscope Strategies on Wind Turbine Gearbox Life Cycle Repair Costs," International Journal of
Prognostics and Health Management, vol. 4, p. 7, 2013.

[8] Asset_Management_Council. (2009) Asset Management. Asset Management Council and MESA Newsletter.

[9] K. O. El-Akruti, "The strategic role of engineering asset management in capital intensive organisations," Dissertation/Thesis, UoW, 2012.

[10] W. J. Fabrycky and B. S. Blanchard, Life-cycle cost and economic analysis. Englewood Cliffs, N.J: Prentice Hall, 1991.

[11] W. Cahyo, "Integrated Maintenance and Inventory Optimization Model for Offshore Assets," presented at the Asia Pacific Industrial Engineering And Management System Conference 2014, Jeju, South Korea, 2014

[12] W. Cahyo, K. El-Akruti, R. Dwight, and T. Zhang, "Managing maintenance resources for better asset utilisation," Australian Journal of Multi-Disciplinary Engineering, vol. 11, 2015.

[13]B. S. Blanchard and W. J. Fabrycky, Systems engineering and analysis. Upper Saddle River, N.J: Pearson, 2011.

[14]R. Dwight, "Frameworks for measuring the performance of the maintenance system in a capital intensive organisation," Doctoral Dissertation/Thesis, University of Wollongong, 1999.

[15]B. S. Dhillon, Life Cycle Costing for Engineers. Ottawa: Taylor and Francis Group, LLC, 2010.

[16] K. El-Akruti, R. Dwight, T. Zhang, and M. AlMarsumi, "The Role of Life Cycle Cost in Engineering Asset Management," presented at the 8th World Congress on Engineering Asset Management \& 3rd International Conference on Utility Management \& Safety, Hong Kong, 2013.

[17]C. E. Ebeling, An introduction to reliability and maintainability engineering. Long Grove, Ill: Waveland Press, 2010.

[18]D. J. Pannell, "Sensitivity analysis of normative economic models: Theoretical framework and practical strategies," Agricultural Economics, vol. 16, 1997. 